\title{
Unraveling the genes implicated in Alzheimer's disease (Review)
}

\author{
MOHAN GIRI, ABHILASHA SHAH, BIBHUTI UPRETI and JAYANTI CHAMLING RAI \\ National Center for Rheumatic Diseases, Ratopul, Kathmandu 44600, Nepal \\ Received November 9, 2016; Accepted May 29, 2017
}

DOI: $10.3892 /$ br.2017.927

\begin{abstract}
Alzheimer's disease (AD) is a heterogeneous neurodegenerative disorder and it is the most common form of dementia in the elderly. Early onset AD is caused by mutations in three genes: Amyloid- $\beta$ precursor protein, presenilin 1 (PSEN1) and PSEN2. Late onset AD (LOAD) is complex and apolipoprotein $\mathrm{E}$ is the only unanimously accepted genetic risk factor for its development. Various genes implicated in AD have been identified using advanced genetic technologies, however, there are many additional genes that remain unidentified. The present review highlights the genetics of early and LOAD and summarizes the genes involved in different signaling pathways. This may provide insight into neurodegenerative disease research and will facilitate the development of effective strategies to combat AD.
\end{abstract}

\section{Contents}

1. Introduction

2. Associated and susceptibility genes of EOAD

3. Genes that confer susceptibility to LOAD/sporadic AD

4. Other susceptible genes of AD

5. Conclusion

\section{Introduction}

Alzheimer's disease (AD), the most common form of dementia among older adults. It is a progressive neurodegenerative disorder, which has been widely recognized as worldwide challenge for society and health-care providers. Clinically, it is defined by progressive loss of cognitive functions, ultimately leading to dementia and mortality (1). Neuropathologically, $\mathrm{AD}$ is characterized by the aggregation and deposition of misfolded proteins, in particular aggregated amyloid- $\beta(\mathrm{A} \beta)$ peptide in the form of extracellular senile (or neuritic)

Correspondence to: Dr Mohan Giri, National Center for Rheumatic Diseases, 4 Pashupati Road, Ratopul, Kathmandu 44600, Nepal

E-mail: mohangiri175@yahoo.com

Key words: Alzheimer's disease, genetics, gene, mutation, biomarker plaques and hyperphosphorylated tau protein in the form of intracellular neurofibrillary tangles (NFTs) (1). Early onset AD (EOAD) affects $<1 \%$ of all AD cases with autosomal dominant inheritance. Late onset AD (LOAD) characterized by a genetically complex and high hereditary pattern of inheritance, is the most common form of the disease with an age of onset $>65$ years (2). Evidence indicates that the major factor of $\mathrm{AD}$ pathogenesis is due to abnormal aggregation and clearance of $A \beta$ by apolipoprotein (Apo) E. However, other potential mechanisms, including modulation of neurotoxicity and tau phosphorylation by Apo E, synaptic plasticity and neuro-inflammation have not been eliminated (3).

The latest advancement in genome wide association studies (GWASs) revealed various candidate genes, which illustrates that LOAD is governed by an array of low penetrance common risk alleles across a number of different loci. EOAD is inherited through an autosomal dominant pattern and is predominantly governed by three rare mutation genes: APP, PSEN1, PSEN2, however, the genetics of LOAD is much more complex. As a result, a large proportion of the heritability of AD remains unexplained by known disease genes (1). In the present study we will have a simple overview of the most susceptible genes of LOAD (sporadic AD), EOAD, and relationship between these genes and the pathogenesis of AD.

\section{Associated and susceptibility genes of EOAD}

EOAD is inherited in an autosomal dominant fashion, which is governed by a rare mutation in three genes: Amyloid precursor protein $(A P P)$ on chromosome 21q, presenilin 1 (PSEN1) on $14 \mathrm{q}$ and presenilin 2 (PSEN2; a homolog of PSEN1) on 1q. Mutation in these three genes causes $\mathrm{AD}$ with high penetrance in mutation carriers (1), with $A \beta$ peptide volume overload and collectively accounts for $<1 \%$ of AD cases in the population. Studies have indicated that rare mutations in these genes exert little effect on or even have no association with LOAD, which indicates that these three gene loci alone do not explain the underlying mechanism of LOAD (Table I).

$A P P$. Located on chromosome 21, APP was the first gene discovered to be associated with EOAD. APP is an integral membrane glycoprotein expressed in the brain and central nervous system (CNS) (4). There are two signaling pathways associated with proteolytic cleaving: The $\alpha$ and $\beta$ pathway, and the former is the most common. The main neuropathological hallmarks of AD are senile plaques and NFTs, which may be associated with brain atrophy and cerebral amyloid angiopathy. 
Table I. Hereditary AD.

\begin{tabular}{|c|c|c|c|}
\hline Name & Associated gene & Locus & Functional pathway \\
\hline AD1 & $A P P$ & $21 \mathrm{q} 21.3$ & $\mathrm{~A} \beta$ generation \\
\hline AD2 & Apolipoprotein E & $19 q 13.32$ & Mediate $A \beta$ levels $\backslash$ lipid transport cholesterol \\
\hline AD3 & Presenilin 1 & $14 \mathrm{q} 24.2$ & $\mathrm{~A} \beta$ clearance and production \\
\hline AD4 & Presenilin 2 & $1 q 42.13$ & Mediate $A \beta$ level \\
\hline AD5 & LDL receptor related protein 1 & $12 \mathrm{p} 11.23-\mathrm{q} 13.13$ & Mediate endocytosis \signaling pathways \\
\hline AD6 & Calcium homeostasis modulator 1 & $10 \mathrm{q} 24$ & Calcium metabolism \\
\hline AD7 & - & $10 \mathrm{p} 13$ & - \\
\hline AD8 & Cystatin $\mathrm{C}$ & $20 p$ & Mediate $\mathrm{A} \beta$ levelVInteract with $A P P$ \\
\hline AD9 & - & $19 \mathrm{p} 13.2$ & - \\
\hline AD10 & - & $7 q 36$ & - \\
\hline AD11 & - & 9 p22.1 & - \\
\hline AD12 & - & $8 \mathrm{p} 12-\mathrm{q} 22$ & - \\
\hline AD13 & - & $1 q 21$ & - \\
\hline AD14 & - & $1 q 25$ & - \\
\hline AD15 & $\begin{array}{l}\text { Nicotinamide nucleotide } \\
\text { adenylyltransferase } 3\end{array}$ & $3 q 22-q 24$ & $\begin{array}{l}\text { Nicotinamide adenine } \\
\text { dinucleotidemetabo lism } \backslash \mathrm{Ca}^{2+} \text { signaling pathways }\end{array}$ \\
\hline AD16 & Protocadherin $11 \mathrm{X}$-linked & $\mathrm{Xq} 21.3$ & Calcium metabolism \\
\hline AD17 & Triggering receptor expressed on myeloid cells 2 & $6 \mathrm{p} 21.1$ & Mediate $\mathrm{A} \beta$ levellinflammation \\
\hline
\end{tabular}

$\mathrm{AD}$, Alzheimer's disease; APP, amyloid- $\beta$ precursor protein; $\mathrm{A} \beta$, amyloid- $\beta$.

The primary component of senile plaques is $\mathrm{A} \beta$ peptides, which are partially generated by the APP gene; although APP acts as the precursor protein for $A \beta$. Endoproteolytic cleavage of APP by two secretases enzymes, $\beta$-secretase and $\gamma$-secretase, produces $A \beta$. In the majority of cases, the $\gamma$-cleavage produces $\mathrm{A} \beta 40$, although it also generates a more toxic variant, $\mathrm{A} \beta 42$ (5). Notably, the catalytic center of $\gamma$-secretase is encoded by the EOAD genes, PSEN1 and PSEN2 (1). Mutation in the APP gene leads to an increased quantity of $A \beta$, which is 2-to 3 -fold higher than normal or non-mutated APP (6). Under normal circumstances, $\alpha$-secretase cleaves APP to produce secreted APP (sAPP) $\alpha$ and membrane-bound C83, while in the amyloidogenic signaling pathway APP is first cleaved by $\beta$-secretase to produce sAPP $\beta$, and subsequently by $\gamma$-secretase to yield $A \beta$ and carboxy-terminal fragment (CTF) $\gamma(7)$. The amyloid cascade hypothesis is the most accepted explanation for the pathogenesis of $A D$, which suggests that $A \beta$ is the principal component of AD pathogenesis (1).

PSEN1 and PSEN2. PSEN1 and PSEN2 have a similar structure and are associated with $\gamma$-secretase activity. Mutations in PSEN1 (AD3) and PSEN2 (AD4) were reported to increase the production of $A \beta$, which results in a larger production of $\mathrm{A} \beta 42$ than $\mathrm{A} \beta 40$, and $\mathrm{A} \beta 42$ tends to be more amyloidogenic and aggregates more easily than A $\beta 40$ (8). PSEN1 mutations may also be associated with cotton wool plaques (9). PSEN2 has a very similar structure and function to PSEN1. Mutations in PSEN2 affect $\gamma$-secretase activity and thus result in an abnormal production of $A \beta 42$.

ATP binding cassette subfamily A member 2 (ABCA2). Recently, an in vitro study demonstrated that ABCA2 was highly expressed in the human neuroblastoma cell line and overexpression of ABCA2 increased transcription of the APP protein (10). A previous study (10) evaluated the temporal and frontal cortex in normal and AD brains, and showed that ABCA2-transfected cells were more resistant to a free radical initiator, which indicated the involvement of ABCA2 in protection against reactive oxygen species and suggested an association with AD. Macé et al (11) found a significant association between a C-T single-nucleotide polymorphism (SNP) in exon 14 of the $A B C A 2$ gene (rs908832) and $\mathrm{AD}$ in a large case-control study involving 440 AD patients, suggesting a strong association between $A B C A 2$ and EOAD (11).

Catenin $\alpha 3$ (CTNNA3). CTNNA3 is a binding partner of catenin $\beta 1$ (CTNNB1). In turn, CTNNB1 interacts with PSEN1, which has many mutations that elevate A $\beta 42$ expression levels and cause early onset familial AD. CTNNA3 was reported to have significant association with LOAD (12) and was also associated with LOAD in females (13).

Prion protein (PRNP). The PRNP gene encodes the prion protein $(\mathrm{PrP})$, which has been implicated in various types of transmissible neurodegenerative spongiform encephalopathies. Being a major component of amyloid plaque, it may increase the risk of AD due to the pathogenic formation of amyloid-like fibrils. There are two wild-type variations in the frequency of V129 and M129 alleles of the PRNP gene. Compared with those with the MV or MM genotypes, those with the $129 \mathrm{VV}$ genotype demonstrate a greater decline in cognitive performance (14). Dermaut et al (14) identified significant association between homozygosity for 129VV and EOAD among 123 Dutch patients, which was stronger in those individuals with a family 
Table II. Sporadic genes associated with Alzheimer's disease.

\begin{tabular}{|c|c|c|}
\hline Gene & Locus & Functional pathway \\
\hline ABCA2 & $9 q 34.3$ & Mediates $A \beta$ level \\
\hline $\mathrm{ACE}$ & $17 q 23.3$ & Metabolism \\
\hline APBB2 & 4p14-p13 & Mediates $A \beta$ level \\
\hline $\mathrm{A} 2 \mathrm{M}$ & $12 \mathrm{p} 13.31$ & Mediates $A \beta$ level \\
\hline BACE1 & $11 \mathrm{q} 23.3$ & Mediates $A \beta$ level \\
\hline BIN1 & $2 q 14.3$ & Mediates $A \beta$ level \\
\hline BLMH & $17 q 11.2$ & Against homocysteine toxicity \\
\hline BSG & $19 \mathrm{p} 13.3$ & Neuroinflammationlimmunoglobulin \\
\hline CALHM1 & $10 q 24.33$ & Calcium metabolism \\
\hline CAPS1 & $11 \mathrm{q} 23$ & Mediates A $\beta$ level \\
\hline CD33 & $19 q 13.41$ & Inflammation\neuroinflammation \\
\hline CLU & $8 \mathrm{p} 21.2$ & Neuroinflammation \lipid transport cholesterol \\
\hline COL25A1 & $4 q 25$ & Senile plaques formation \\
\hline CR1 & $1 q 32.2$ & Inflammation\neuroinflammation \\
\hline CST3 & 20p11.21 & Mediates cerebral amyloidosis \\
\hline CTNNA3 & $10 \mathrm{q} 21.3$ & Interact with PSEN1/mediate $A \beta$ level \\
\hline CYP2D6 & $22 q 13.2$ & Metabolism \\
\hline GAL & $11 \mathrm{q} 13.3$ & Drug metabolism \\
\hline HFE & $6 \mathrm{p} 22.2$ & Iron metabolism \\
\hline HTR7 & $10 q 23.31$ & G-protein receptor $\backslash$ metabolism \\
\hline IDE & $10 q 23.33$ & Mediates $A \beta$ level \\
\hline LRP1 & $12 q 13.3$ & Signal transduction\metabolism \\
\hline MAPT & $17 q 21.31$ & Mediates tau level \\
\hline MS4A & $11 \mathrm{q} 12.2$ & Inflammation\neuroinflammation \\
\hline MPO & $17 q 22$ & Antimicrobial oxidantlinflammation \\
\hline NOS3 & $7 q 36.1$ & Metabolism \\
\hline PICALM & $11 \mathrm{q} 14.2$ & Mediates $A \beta$ level \\
\hline PLAU & $10 \mathrm{q} 22.2$ & Mediates $A \beta$ level \\
\hline PRNP & $20 \mathrm{p} 13$ & Formation of amyloid-like fibrils \\
\hline SORL1 & $11 \mathrm{q} 24.1$ & Mediates $A \beta$ level \\
\hline UBQLN1 & $9 q 21.32$ & Mediates $A \beta$ level \\
\hline
\end{tabular}

history. In a previous study of 482 AD patients, including 138 with onset aged $<60$ years, Riemenschneider et al (15) found that the 129MM genotype conferred an increased risk of developing $\mathrm{AD}$ in the early onset group (odds ratio, 1.92; $\mathrm{P}=0.013$ ), which was more marked in those patients without the APOE \&4 allele. This demonstrated that individuals exhibiting heterozygosity for a common polymorphism in the human PrP confer more resistance to prion diseases (15).

\section{Genes that confer susceptibility to LOAD/sporadic AD}

The underlying mechanism of mutations in genes causing LOAD is markedly more complicated than that of EOAD. To date, Apo $\mathrm{E}$ is the only unanimously accepted genetic risk factor for the development of sporadic $\mathrm{AD}$ and the $\varepsilon 4$ allele for $A P O E$ has been implicated in LOAD (1). However, there are numerous susceptibility genes associated with LOAD (Table II), with the predominant function of certain susceptibility genes being mediating $A \beta$ expression levels, whilst others are implicated in metabolic pathways.
Genes that mediate A $\beta$ expression levels

$A P O E$. Located on the long arm of chromosome 19, the $A P O E$ gene is confirmed as a susceptibility gene locus of $\mathrm{AD}$, which is significant in familial and sporadic AD cases. $A P O E$ is considered to be a genetic risk factor rather than a disease-causing mutation for LOAD. The three most common SNPs in the APOE gene lead to changes in the coding sequence and result in three common forms of Apo E: Apo E $\varepsilon 2$ (cys112, cys158), Apo E ع3 (cys112, arg158)and Apo E ع4 (arg112, $\arg 158)$. Apo E is key in lipoprotein metabolism and cholesterol transport in plasma and the nervous system (1). Sufficient evidence indicates that different forms of Apo $\mathrm{E}$ have diverse effects on the aggregation and clearance of $A \beta(16)$. Apo $E \varepsilon 3$ is the most common form of all the $A P O E$ alleles, which serves a more significant role than Apo E $\varepsilon 4$ in delivering cholesterol to neurons. Apo E $\varepsilon 2$ is associated with a decreased risk for AD, while Apo E $\varepsilon 4$ is regarded as the strongest risk factor for AD. Compared with Apo E ع4, Apo Eع2 and Apo E $\varepsilon 3$ may enhance the clearance of $A \beta$ and thus Apo E $\varepsilon 4$ may be associated with an increased risk for LOAD (3). 
Previous studies have found that Apo E $\varepsilon 4$ was more efficient than Apo E $\varepsilon 3$ and Apo Eع2 in increasing $A \beta 40$ aggregation $(3,17,18)$. Apo $\mathrm{E}$ may be important in the clearance of A $\beta$. Various in vitro studies have demonstrated that Apo E enhances cellular $A \beta$ uptake and degradation; thus, the blood-brain barrier must be considered as a potential pathway of $A \beta$ clearance in the brain, particularly via low density lipoprotein receptor-related protein1 (LRP1) $(3,19)$. Apo E has been shown to promote the deposition of $A \beta$ plaques and NFTs, thus leading to the development of AD (1).

Amyloid- $\beta$ precursor protein binding family $B$ member 2 (APBB2). The APBB2 (or Fe65-like sequence; FE65L1) gene encodes for theAPBB2 protein. Li et al (20) performed a genetic association study of APBB2 and LOAD, and demonstrated that one SNP (rs13133980), located in a region conserved between the human and mouse genomes, was associated with age of disease onset. Golanska et al (21) found that severe cognitive impairment in centenarians was due to the over expression of APBB2 rs13133980 G.

Plasminogen activator, urokinase (PLAU). Urokinase plasminogen activator (uPA; PLAU) converts plasminogen to plasmin, which is involved in the processing of APP and degrades secreted and aggregated $\mathrm{A} \beta(22)$. The $P L A U$ gene is located on chromosome 10, maps to the AD6 critical region, which is associated with LOAD, with allele $\mathrm{C}$ being a recessive risk allele and allele $\mathrm{T}$ conferring protection (22). A previous study by Ozturk et al (23) revealed that SNP rs2227571 in intron 9 and s4065 in the 3'- untranslated region (UTR) revealed a significant association with AD. Recently, a meta-analysis comprising 6,100 AD cases and 5,718 control subjects showed that the T allele of the rs2227564 polymorphism in the PLAU gene was associated with an increased risk of AD (24).

Triggering receptor expressed on myeloid cells 2 (TREM2). TREM2 is a transmembrane glycoprotein that consist of an extracellular immunoglobulin-like domain, a transmembrane domain and a cytoplasmic tail, which encodes a single-pass type I membrane protein that forms a receptor-signaling complex with the TYRO protein tyrosine kinase-binding protein (TYROBP, also termed DAP12) and, thereby, triggers the activation of immune responses in macrophages and dendritic cells (25-27). Previous studies have revealed the association of TREM 2 with LOAD, and have also shown that a rare variant in this gene (SNP rs75932628-T) increases the risk for AD by up to 5 -fold $(26,28,29)$. Acting as an innate immune receptor and DAP12-associated receptor, TREM2 is expressed widely on the surface of cells, such as macrophages, microglia, osteoclasts and immature dendritic cells (30).

The expression level of TREM2 is high in white matter, moderate in the hippocampus and neocortex, but lowest in the cerebellum (28). A rare functional variant $(\mathrm{R} 47 \mathrm{H})$ in TREM2 has been associated with the pathological features reported in the AD brain and Nasu-Hakola disease, a rare form of autosomal recessive disorder, characterized by multiple bone cysts that leads to dementia associated with bone cystic lesions (27). In addition, loss-of-function mutations in TREM2 and DAP12 was associated with the Nasu-Hakola disease (25). Furthermore, homozygous and heterozygous loss-of-function mutations in TREM2 have been associated with early onset dementia, as well as with Nasu-Hakola disease (28). TREM2 is mainly associated with the clearance of neural debris, such as apoptotic neural tissue in the impaired nervous system. However, the endogenous ligand of the lesioned neural tissue that is recognized by TREM2 remains unknown (26). Furthermore, there is an anti-inflammation cytokine milieu subsequent toTREM 2 combining with DAP12, which mediates the clearance of neural debris. The TREM2 variants (the R47H substitution) may exacerbate inflammatory cascades, thus inciting systemic inflammatory response and the death of neurons (27). There is a positive correlation between the increased TREM2 expression and increased cortical levels of $\mathrm{A} \beta$; however, the dysregulation of expression that is induced by $A \beta$ is relatively specific to TREM2 (27). Previous studies have also revealed the role of TREM 2 in $A \beta$ accumulation and ageing (31). Thus, TREM 2 variants cause $A D$ via downregulation of the $A \beta$ phagocytic ability of microglia and via the dysregulation of the pro-inflammatory response of these cells.

Phosphatidylinositol binding clathrin assembly protein (PICALM). The association between $\mathrm{AD}$ and the gene encoding PICALM variants have been demonstrated in previous studies $(32,33)$. PICALM is located on chromosome 11q14.2 and is largely restricted to endothelial cells, with a low expression level in neurons and glial cells. PICALM promotes clathrin-mediated endocytosis and facilitates with presynaptic endocytosis (34). PICALM has been associated with A $\beta$ production and APP processing $(33,34)$. Recently, the role of PICALM in tau clearance and autophagy wasimplicated as a multifunctional protein (35). PICALM interacts with bridging integrator 1 (BIN1) for the intracellular trafficking of proteins, lipids, growth factors and neurotransmitters. In addition, the intracellular trafficking of synaptic vesicle, vesicle-associated membrane protein 2 , is conducted by PICALM, which is vital to memory formation and neuronal function. Furthermore, the PICALM protein is predominately expressed in endothelial cells, where it may contribute to $A \beta$ clearance into the bloodstream (36). The transport of $A \beta$ across vessel walls and into the bloodstream is a major pathway of $A \beta$ removal from the brain, and the impairment of which is proposed to be important in the development of AD (36). An increased expression level of SNP rs3851179 located upstream of the coding region was found to be protective against AD (37). In addition, Schjeide et al (38) demonstrated that only rs541458 in PICALM was shown to affect cerebrospinal fluid (CSF) protein levels, suggesting that the AD risk allele is associated with decreased CSF A $\beta 42$ expression levels, which provides an insight into the potentially predominant pathogenetic mechanism underlying the association between AD risk and PICALM (38).

BIN1. Located on chromosome2q14.3, BIN1 has various forms and it is abundantly expressed in the brain. BINl (also termed amphiphysin II) encodes various forms of an adaptor protein involved in receptor-mediated endocytosis, which may have an effect on $A \beta$ production and/or the clearance of $A \beta$ from the brain (1). BIN1 may bind to integrin $\alpha 3$ to mediate adhesion and detachment of migrating neurons from radial 
glial fibers in mice $(39,40)$. Notably, BIN1 has been implicated in cell-to-cell communication and signal transduction $(40,41)$. In addition to the locus, rs744373, near BIN1, a GWAS identified additional loci emerging simultaneously with BINI from the SNPrs597668 near exocyst complex component 3 -like 2 /biogenesis of lysosomal organelles complex 1 subunit $3 /$ microtubule affinity regulating kinase 4 , which was associated with LOAD (41).

Sortilin-related receptor (SORL1). SORL1 encodes a mosaic protein that is a member of the vacuolar protein sorting-10 domain-containing receptor family and the low-density lipoprotein receptor family (42). SORL1 mediates the transport of vesicles from the cell surface to the Golgi apparatus and endoplasmic reticulum, which is vital in APP processing. According to Sager et al (43), decreased SORL1 expression levels reflects cognitive performance and may predispose individuals with mild cognitive impairment to the development of AD (43). Recently Louwersheimer et al (44) demonstrated that SORL1 SNP rs2070045G allele was correlated with hippocampal atrophy and CSF-tau, suggesting the role of SORL1 in AD pathology.

Insulin-degrading enzyme (IDE). IDE (also termedinsulysin) is a $110-\mathrm{kD}$ neutral metallopeptidase that decreases the level of numerous of peptides, such as insulin and A $\beta$.IDE is involved in the clearance of extracellular A $\beta$ (45). Extracellular IDE may be key in the clearance of $A \beta$ and can be associated with AD. Furthermore, Apo E, which is major risk factor for LOAD, enhances IDE activity (46). In a previous study, a reduction of the IDE level by $50 \%$ in AD patients with the Apo E $\varepsilon 4$ allele compared with those without the Apo E $\varepsilon 4$ allele indicated that decreased IDE may be risk factor for AD (47).

a2-macroglobulin (A2M). The A2M gene is located on chromosome $12 \mathrm{p} 13.31$. The $A 2 M$ gene encodes A2M, and it inhibits numerous proteases, such as trypsin, thrombin and collagenase (48). A2M acts as an extracellular chaperone and is involved in the clearance of extracellular $A \beta(49,50)$. The role of $\mathrm{A} 2 \mathrm{M}$ in inflammation and amyloid fibril formation suggests that $\mathrm{A} 2 \mathrm{M}$ expression is critical in the pathogenesis of $\mathrm{AD}(51,52)$.

Ubiquilin 1 (UBQLN1). The gene coding for UBQLN1 is located on chromosome 9q22.2.UBQLN1, also termed proteins linking integrin-associated protein, has two haplotypes, haplotype $\mathrm{H} 4$, which is associated with AD risk andH5, which is associated with protection (53). UBQLN1 regulates APP maturation and acts as a chaperone for APP $(54,55)$. Overexpression of UBQLN1 results in a reduced $A \beta 42 / A \beta 40$ ratio while APP-induced toxicity is increased by knockdown of UBQLN1 (54). Thus, reduced UBQLN1 expression may contribute to the pathogenesis of AD.

\section{Genes implicated in the metabolic pathway}

Nitric oxide synthase 3 (NOS3). NOS3 gene encodes NOS3 and is located on chromosome 7q35. Nitric oxide (NO) may be involved in oxidative stress-induced neurodegeneration in AD (56). A meta-analysis by Liu et al (57) demonstrated that there was a significant association between the NOS3 G894T polymorphism and risk of $\mathrm{AD}$ (57). Increased expression levels of A $\beta$ and APP, and impaired spatial memory were demonstrated by Austin et al (58) in NOS-deficient mice. Thus, the pathogenesis of sporadic AD may results from a deficiency of endothelial NO.

Nicotinamide nucleotide adenylyltransferase 3 (NMNAT3) and calsyntein 2 (CLSTN2). NMNAT3 is located on chromosome 3q23. The SNP rs952797, which is downstream of the gene encoding NMNAT3 and upstream of the gene encoding CLSTN2, was demonstrated to be associated with AD (59). The NMNAT3 gene is key in nucleotide adenylyltransferase (NAD) synthesis and involved in AD (60). Recently NMNAT3 deficiency was identified to be associated with hemolytic anemia (61).

Calcium homeostasis modulator 1 (CALHM1). CALHM1 is a key modulator of intracellular $\mathrm{Ca}^{2+}$ homeostasis, which maps to the AD6 region on chromosome 10q24.33 (62). Altered $\mathrm{Ca}^{2+}$ metabolism may lead to the development of AD (63). SNP rs2986017 polymorphism in the CALHMI gene has been associated with LOAD risk $(62,64)$. In cohorts with an increased risk of $\mathrm{AD}$, Koppel et al (65) revealed that the P86L polymorphism was associated with elevated CSF A $\beta 42$ and $A \beta 40$ levels. The latest findings demonstrated that a rare genetic variant in CALHM1 alters $\mathrm{Ca}^{2+}$ homeostasis and may contribute to the development of EOAD (66).

5-Hydroxytryptamine receptor 7 (5-HTR7). HTR7 is a $\mathrm{G}$ protein-coupled receptor for serotonin. According to Liu et al (59) HTR7 was associated with LOAD on chromosome 10q22-24. In their association study three SNPs, rs17129662, rs11185978 and rs7071717 together at $91.7 \mathrm{Mb}$, demonstrated an association with multiple cognitive domains in 197 unrelated subjects (59). Perez-García and Meneses (67) revealed that selective 5-HTR7 agonists are useful in the treatment of dysfunctional memory in aged-associated decline and AD.

Angiotensin-converting enzyme (ACE). The ACE gene is located on chromosome $17 \mathrm{q} 23$ and is expressed in the brain. $\mathrm{ACE}$ may influence $\mathrm{A} \beta$ metabolism (68). In vitro and in vivo studies have indicated that ACE functions to degrade $A \beta$ and low ACE activity may increase the risk of $\operatorname{AD}(68,69)$. Although the association of ACE inhibitor and risk of AD remains unclear, Qiu et al (70) revealed a positive correlation between ACE inhibitor use and AD among APO $\varepsilon 4$ carriers.

LRP1. LRP1 is located on chromosome 12q13.3 and is involved in intracellular signaling, lipid homeostasis and clearance of apoptotic cells. LRP1 mediates the transport of $\mathrm{A} \beta$, which in turn prevents synaptic dysfunction and neurodegeneration (71).Impaired clearance of A $\beta$ by LRP1 is associated with accelerated $\mathrm{A} \beta$ and $\mathrm{AD}$ progression (71). Jaeger et al (72) also revealed that dysfunction of LRP1 at the blood brain barrier may be associated with increased $\mathrm{A} \beta$ accumulation and progression of AD. Recently, LRP1 was associated with downregulation of $\beta$-site APP-cleaving enzyme 1 (BACE1) and, thus, affects generation of $A \beta$ by cleavage of the APP (73). 
Genes regulating neuroinflammation

Membrane-spanning 4-domains (MS4A). The MS4A genes are located on chromosome 11q12 in humans. Proteins in the MS4A family share similar structures, amino acid sequence homology and chromosomal location. Various members of MS4A (including MS4A3, MS4A2, MS4A6A, MS4A4A, MS4A4E and MS4A6E) are significant in immunity, indicating the possible involvement of the MS4A gene cluster in AD pathogenesis (74). LOAD GWAS have identified various SNPs as follows; rs983392 and rs610932 at MS4A6A, associated with decreased AD risk, and SNP rs610932 near MS46A, associated with increased AD risk (75-77). The MS4A family modulates $\mathrm{Ca}^{2+}$ homeostasis and increased levels of intracellular $\mathrm{Ca}^{2+}$ lead to neuronal death. Thus, overexpression of the $M S 4 A$ gene may result in immune system dysfunction.

CD33. CD33 is a transmembrane protein located on chromosome 19q13.3 that is expressed on myeloid cells and microglia (78). CD33 mediates endocytosis independent of clathrin and may be key in A $\beta$ clearance. In LOAD GWAS, the CD33 rs3865444 polymorphism was associated with the risk for AD (75,76). Recently, Bao et al (79) revealed that the rs3865444 allele was associated with decreased AD risk; however, the association differed significantly between the Asian and Caucasian group. Bradshaw et al (80) identified that $\mathrm{CD} 33$ is important in $\mathrm{A} \beta$ clearance. The authors found that the ability of monocytes to phagocytose $A \beta$ is inhibited by increased expression levels of CD33 on the surface of circulating monocytes (80).

Clusterin (CLU) and complement receptor 1 (CR1). Inflammation plays a primary role in the development AD. CLU and CR1 demonstrate marked responses to inflammation and innate or adaptive immunity. CR1 is the main receptor of the complement $\mathrm{C} 3 \mathrm{~b}$ protein, a key inflammatory protein activated in $\mathrm{AD}(81)$. CLU is one of the major Apo in the brain, and may be involved in synaptic turnover and apoptosis (82). Located on chromosome 8p21.1, SNP rs9331896 of CLU was associated with LOAD (77). The progression of AD and brain atrophy is significantly associated with increased plasma CLU levels (83). The $C R I$ gene is located on chromosome 1q32, and is widely expressed on B lymphocytes, monocytes, macrophages, erythrocytes and dendritic cells (84). CR1 may be involved in innate and adaptive immune responses (85). In addition, $\mathrm{CR} 1$ is important in $\mathrm{AD}$ pathogenesis as it contributes to mediating neuroinflammation and activating the complement system (86). In LOAD GWAS, SNPs rs6656401 and rs3818361 were associated with the risk of LOAD (33). The plaque load in the brain of patients with AD was identified to be associated with SNP rs1408077 of CRl (87).

\section{$X$-linked inheritance}

Protocadherin $11 X(P C D H 11 X)$. PCDH11X/Y belongs to the protocadherin gene subfamily of the cadherin super family of cell surface receptor molecules and is located on chromosome Xq21.2/Yp11.2. The cadherins facilitate cell signaling and $\mathrm{Ca}^{2+}$-dependent cell adhesion, which is important for development of the CNS (88). Carrasquillo et al (89) revealed that genetic variation in PCDH11X was strongly associated with LOAD susceptibility. The authors found that SNP rs5984894 on Xq21.3 in PCDH11X was strongly associated with LOAD in individuals of European descent from the USA. PCDH11X is highly expressed in the cerebral cortex and hippocampus. Furthermore, $P C D H 11 X$ is considered as a good candidate gene for PSEN-dependent processing and neurodegeneration (90).

\section{Other susceptible genes of AD}

Hemochromatosis (HFE). The HFE gene is located on chromosome $6 \mathrm{p} 21.3$ and it functions to regulate iron absorption. Iron imbalance may affect plaque formation and amyloid processing. Thus, loss of iron homeostasis can be central to the pathogenic events in AD (91). Furthermore, iron is important in the pathology of $\mathrm{AD}$; thus, genetic factors that contribute to iron deposition resulting in tissue damage may exacerbate AD (92). Mutation of the HFE gene increases the risk of AD $(93,94)$. Lehmann et al $(95)$ revealed that iron overload may be a causative factor in the development of AD.

Bleomycinhydrolase(BLMH).BLMH is located onchromosome $17 \mathrm{q} 11.2$ and is vital in homocysteine-thiolactone metabolism, AD pathogenesis and antigen presentation (96). BLMH participates in homocysteine metabolism and homocysteine is a risk factor for AD. Recently, Suszyńska-Zajczyk et al (97) revealed that BLMH is key in cytoskeleton dynamics, maintains synaptic plasticity, and inactivation of the $B L M H$ gene may be associated with AD.

Myeloperoxidase (MPO). MPO is abundant in A $\beta$ plaques in the AD brain and has potent antimicrobial oxidizing abilities (98). MPO may enhance macrophage generation and the expression levels of proinflammatory cytokines $(98,99)$. Maki et al (99) demonstrated that lipid peroxide produced by MPO radical may lead to memory loss, neuronal dysfunction and AD. In addition, a study by Tzikas et al (100) demonstrated a possible association of MPO with the plasma A $\beta$ 1-42/1-40 ratio and the authors concluded that elevated plasma levels of MPO may be associated with AD pathogenesis.

Cystatin C (CST3). CST3 is located on chromosome 20p11.21 and is expressed by neurons, astrocytes and microglial cells in the brain. CST3 is involved in neuronal degeneration, but recent data showed that CST3 may exert protective effects in AD by induction of autophagy and proliferation, and inhibition of $A \beta$ aggregation (101). A previous study identified that AD patients have low CSF levels of CST3 when compared with control subjects (102). CST3 polymorphism is associated with AD (103). In addition, CST3 exerts a protective effect in AD by preventing the formation of toxic forms of A $\beta$ (104). A previous study with transgenic mice demonstrated the association of CST3 with non-toxic forms of A $\beta$ and prevention of $A \beta$ plaque formation (105). In addition, the authors revealed that reduced levels of CST3 may impair the neuronal ability to prevent neurodegeneration in AD (105). Recently, Butler et al (106) found that a missense variant in CST3 rs1064039 was associated with age-associated macular degeneration and $\mathrm{AD}$. 
Microtubule-associated protein tau (MAPT). The MAPT (microtubule-associated protein tau) gene is located on chromosome 17q21.1 and is predominantly expressed in neurons. MAPT functions in axonal transport, assembly and stabilization of microtubules. NFTs in AD are primarily due to hyperphosphorylation of MAPT (107). Furthermore, tau is phosphorylated by protein kinases, such as glycogen synthase kinase 3 and cyclin-dependent kinase $5(107,108)$. A previous study demonstrated that the MAPT H1c sub haplotype was associated with LOAD risk (108).

$\beta$-site APP-cleaving enzyme 1 (BACE1). BACE1, also termed $\mathrm{ASP} 2$, is the enzyme responsible for initiating $\mathrm{A} \beta$ generation. $\gamma$-secretase and BACE1 are required for the generation of $A \beta$ by the processing of APP (109). A previous study demonstrated that BACE1 activity is increased in AD brains (110). Recently, Cheng et al (111) demonstrated that BACE1 enzymatic activity increased in mild cognitive impairment (MCI) and may be responsible for the development of MCI into AD. In an experiment with APP transgenic mouse, knockdown of either BACE or BASE1-antisense transcript (BACE1-AS) homologs caused concordant downregulation of BACE or BACE1-AS homolog, which was followed by a reduction in insoluble $\mathrm{A} \beta$ production and $A \beta$ aggregation, and normalization of markers of adult neurogenesis (112).

Collagen XXVal (COL25A1). COL25A1 is located on chromosome $4 \mathrm{q} 25$ and is collagenous type II transmembrane protein purified from senile plaques of AD brains. In a Swedish population, COL25A1 was associated with increased AD risk (113). In an experiment with mice, overexpression of COL25A1 was associated with $\mathrm{A} \beta$ accumulation and increased BACE1 levels, as well as loss of synaptophysin, astrocyte activation and behavioral abnormalities, these finding indicated that COL25A1 may be involved in the pathogenesis of AD (114).Previously, Li et al (115) identified that COL25A1 was associated with antisocial personality disorder and substance dependence.

Caspase-1 (CASP1). CASP1 is located on chromosome $11 \mathrm{q} 23$ and encodes a protein, which is a member of the cysteine-aspartic acid protease family. CASP1 regulates inflammatory processes by activation of proinflammatory cytokines, such as interleukin (IL)-1 $\beta$ (IL1B), IL-18 and IL-33 precursor proteins, and it regulates the proteins involved in tissue repair and cytoprotection (116).Heneka et al (117) revealed that CASP1 is expressed in human mild cognitive impairment and brains of patients with AD. Furthermore, CASP1-derived inflammatory mediators were involved in mediating synaptic dysfunction and cognitive impairment. The role of NACHT, LRR and PYD domains-containing protein 3 inflammasome in the $A \beta$-mediated inflammatory process indicated that CASP1 may be involved in AD pathogenesis (117).

Cytochrome P450 family 2 subfamily D member 6 (CYP2D6). CYP2D6 is located on chromosome 22q13.1 and encodes a member of the cytochrome P450 superfamily of enzymes. The hepatic cytochrome $\mathrm{P} 450$ system is responsible for catalyzing various reactions involved in drug metabolism and synthesis of cholesterol, steroids and other lipids. APOE may influence CYP2D6-associated enzyme and drug metabolism by modifying hepatic steatosis and transaminase activity in the liver (118). CYP2D6 was closely associated with the dopamine transporter and rat brain-specific CYP2D18 has been implicated in dopamine metabolism (119). Pilotto et al (120) demonstrated that, in patients with mild to moderate AD, SNP rs1080985 in CYP2D6 may influence the clinical efficacy of donepezil. Whereas, Liu et al (121) found no significant association between rs1080985 SNP in CYP2D6 and common APOE polymorphisms in a Chinese population.

Galanin (GAL). The neuropeptide, GAL is located on chromosome 11q13.3 and regulates cognitive behaviors. GAL inhibits cholinergic neurotransmission and $G A L$ overexpression enhances AD progression (122). Overexpression of GAL in transgenic mice was associated with cognitive deficit, suggesting that increased expression levels of GAL may lead to neurochemical and cognitive impairments similar to those in $\mathrm{AD}$ (123).

Basigin (BSG). BSG (also termed CD147) is a member of the immunoglobulin super family, which is important in fetal, neuronal, lymphocyte and extracellular matrix development. Zhou et al (124) revealed CD147 as a regulatory component of the $\gamma$-secretase complex. Furthermore, depletion of CD147 by RNA interference was associated with increased $A \beta$ production, indicating that the presence of the CD147 subunit within the $\gamma$-secretase complex decreased the production of A $\beta$-peptides (124).

\section{Conclusion}

$\mathrm{AD}$ is the most common neurodegenerative disease and is widely recognized as a global challenge for society and health-care providers. EOAD is inherited via an autosomal dominant pattern and predominantly governed by three rare mutation genes as follows: APP, PSEN1, and PSEN2, through a common mechanism of altered $\mathrm{A} \beta$ production. In addition, APOE has been recognized as a major genetic risk factor for LOAD. Furthermore, various genes have been implicated in LOAD; these genes primarily mediate the A $\beta$ level, while certain genes are implicated in the metabolic pathway and neuroinflammation. Further studies are required to unravel the complete picture of genetics behind this devastating disease and to provide insight into novel therapeutic targets.

\section{References}

1. Bertram L, Lill CM and Tanzi RE: The genetics of Alzheimer disease: Back to the future. Neuron 68: 270-281, 2010.

2. Tanzi RE: The genetics of Alzheimer disease. Cold Spring Harb Perspect Med 2: a006296, 2012.

3. Kim J, Basak JM and Holtzman DM: The role of apolipoprotein E in Alzheimer's disease. Neuron 63: 287-303, 2009.

4. Puig KL and Combs CK: Expression and function of APP and its metabolites outside the central nervous system. Exp Gerontol 48: 608-611, 2013.

5. De Strooper B, Vassar R and Golde T: The secretases: Enzymes with therapeutic potential in Alzheimer disease. Nat Rev Neurol 6: 99-107, 2010.

6. Zhou L, Brouwers N, Benilova I, Vandersteen A, Mercken M, Van Laere K, VanDammeP,DemedtsD, VanLeuvenF, Sleegers K, et al: Amyloid precursor protein mutation $\mathrm{E} 682 \mathrm{~K}$ at the alternative $\beta$-secretase cleavage $\beta$ '-site increases $\mathrm{A} \beta$ generation. EMBO Mol Med 3: 291-302, 2011. 
7. Zhang $X$ and Song W: The role of APP and BACE1 trafficking in APP processing and amyloid- $\beta$ generation. Alzheimers Res Ther 5: 46, 2013.

8. Cohen SI, Linse S, Luheshi LM, Hellstrand E, White DA, Rajah L, Otzen DE, Vendruscolo M, Dobson CM and Knowles TP: Proliferation of amyloid- $\beta 42$ aggregates occurs through a secondary nucleation mechanism. Proc Natl Acad Sci USA 110: 9758-9763, 2013.

9. Le TV, Crook R, Hardy J and Dickson DW: Cotton wool plaques in non-familial late-onset Alzheimer disease. J Neuropathol Exp Neurol 60: 1051-1061, 2001.

10. Davis W Jr: The ATP-Binding Cassette Transporter-2 (ABCA2) Overexpression modulates sphingosine levels and transcription of the amyloid precursor protein (APP) gene. Curr Alzheimer Res 12: 847-859, 2015.

11. Macé S, Cousin E, Ricard S, Génin E, Spanakis E, Lafargue-Soubigou C, Génin B, Fournel R, Roche S, Haussy G, et al: ABCA2 is a strong genetic risk factor for early-onset Alzheimer's disease. Neurobiol Dis 18: 119-125, 2005.

12. Ertekin-Taner N, Graff-Radford N, Younkin LH, Eckman C, Baker M, Adamson J, Ronald J, Blangero J, Hutton M and Younkin SG: Linkage of plasma Abeta42 to a quantitative locus on chromosome 10 in late-onset Alzheimer's disease pedigrees. Science 290: 2303-2304, 2000

13. Miyashita A, Arai H, Asada T, Imagawa M, Matsubara E, Shoji M, Higuchi S, Urakami K, Kakita A, Takahashi H, et al; Japanese genetic study consortium for Alzeheimer's disease: Genetic association of CTNNA3 with late-onset Alzheimer's disease in females. Hum Mol Genet 16: 2854-2869, 2007.

14. Dermaut B, Croes EA, Rademakers R, Van den Broeck M, Cruts M, Hofman A, van Duijn CM and Van Broeckhoven C: PRNP Val129 homozygosity increases risk for early-onset Alzheimer's disease. Ann Neurol 53: 409-412, 2003.

15. Riemenschneider M, Klopp N, Xiang W, Wagenpfeil S, Vollmert C, Müller U, Förstl H, Illig T, Kretzschmar H and Kurz A: Prion protein codon 129 polymorphism and risk of Alzheimer disease. Neurology 63: 364-366, 2004.

16. Yu JT, Tan L and Hardy J: Apolipoprotein E in Alzheimer's disease: An update. Annu Rev Neurosci 37: 79-100, 2014

17. Castano EM, Prelli F, Wisniewski T, Golabek A, Kumar RA, Soto $\mathrm{C}$ and Frangione B: Fibrillogenesis in Alzheimer's disease of amyloid $\beta$ peptides and apolipoprotein E. Biochem J 306 : 599-604, 1995

18. Wisniewski T, Castaño EM, Golabek A, Vogel T and Frangione B: Acceleration of Alzheimer's fibril formation by apolipoprotein $\mathrm{E}$ in vitro. Am J Pathol 145: 1030-1035, 1994.

19. Zlokovic BV: Cerebrovascular effects of apolipoprotein E: Implications for Alzheimer disease. JAMA Neurol 70: 440-444, 2013.

20. Li Y, Hollingworth P, Moore P, Foy C, Archer N, Powell J, Nowotny P, Holmans P, O'Donovan M, Tacey K, et al: Genetic association of the APP binding protein 2 gene (APBB2) with late onset Alzheimer disease. Hum Mutat 25: 270-277, 2005.

21. Golanska E, Sieruta M, Gresner SM, Pfeffer A, Chodakowska-Zebrowska M, Sobow TM, Klich I, Mossakowska M, Szybinska A, Barcikowska M, et al: APBB2 genetic polymorphisms are associated with severe cognitive impairment in centenarians. Exp Gerontol 48: 391-394, 2013

22. Finckh U, van Hadeln K, Müller-Thomsen T, Alberici A, Binetti G, Hock C, Nitsch RM, Stoppe G, Reiss J and Gal A: Association of late-onset Alzheimer disease with a genotype of PLAU, the gene encoding urokinase-type plasminogen activator on chromosome 10q22.2. Neurogenetics 4: 213-217, 2003

23. Ozturk A, Minster RL, DeKosky ST and Kamboh MI: Association of tagSNPs in the urokinase-plasminogen activator (PLAU) gene with Alzheimer's disease and associated quantitative traits. Am J Med Genet B Neuropsychiatr Genet 144B: 79-82, 2007.

24. Wu W, Jiang $\mathrm{H}$, Wang $\mathrm{M}$ and Zhang D: Meta-analysis of the association between urokinase-plasminogen activator gene rs2227564 polymorphism and Alzheimer's disease. Am J Alzheimers Dis Other Demen 28: 517-523, 2013.

25. Paloneva J, Kestilä M, Wu J, Salminen A, Böhling T, Ruotsalainen V, Hakola P, Bakker AB, Phillips JH, Pekkarinen P, et al: Loss-of-function mutations in TYROBP (DAP12) result in a presenile dementia with bone cysts. Nat Genet 25: 357-361, 2000.

26. Neumann H and Daly MJ: Variant TREM 2 as risk factor for Alzheimer's disease. N Engl J Med 368: 182-184, 2013.

27. Guerreiro R, Wojtas A, Bras J, Carrasquillo M, Rogaeva E, Majounie E, Cruchaga C, Sassi C, Kauwe JS, Younkin S, et al: Alzheimer Genetic Analysis Group: TREM2 variants in Alzheimer's disease. N Engl J Med 368: 117-127, 2013.
28. Singaraja RR: TREM2: A new risk factor for Alzheimer's disease. Clin Genet 83: 525-526, 2013.

29. Jonsson T, Stefansson H, Steinberg S, Jonsdottir I, Jonsson PV Snaedal J, Bjornsson S, Huttenlocher J, Levey AI, Lah JJ, et al: Variant of TREM2 associated with the risk of Alzheimer's disease. N Engl J Med 368: 107-116, 2013.

30. Hickman SE and El Khoury J: TREM2 and the neuroimmunology of Alzheimer's disease. Biochem Pharmacol 88: 495-498, 2014.

31. Wang Y, Cella M, Mallinson K, Ulrich JD, Young KL, Robinette ML, Gilfillan S, Krishnan GM, Sudhakar S, Zinselmeyer BH, et al: TREM2 lipid sensing sustains the microglial response in an Alzheimer's disease model. Cell 160 1061-1071, 2015

32. Harold D, Abraham R, Hollingworth P, Sims R, Gerrish A, Hamshere ML, Pahwa JS, Moskvina V, Dowzell K, Williams A, et al: Genome-wide association study identifies variants at CLU and PICALM associated with Alzheimer's disease. Nat Genet 41: 1088-1093, 2009.

33. Lambert JC, Heath S, Even G, Campion D, Sleegers K, Hiltunen M, Combarros O, Zelenika D, Bullido MJ, Tavernier B, et al: European Alzheimer's Disease Initiative Investigators: Genome-wide association study identifies variants at CLU and CR1 associated with Alzheimer's disease. Nat Genet 41: 1094-1099, 2009.

34. Koo SJ, Markovic S, Puchkov D, Mahrenholz CC, Beceren-Braun F, Maritzen T, Dernedde J, Volkmer R, Oschkinat $\mathrm{H}$ and Haucke V: SNARE motif-mediated sorting of synaptobrevin by the endocytic adaptors clathrin assembly lymphoid myeloid leukemia (CALM) and AP180 at synapses. Proc Natl Acad Sci USA 108: 13540-13545, 2011.

35. Moreau K, Fleming A, Imarisio S, Lopez Ramirez A, Mercer L, Jimenez-Sanchez M, Bento CF, Puri C, Zavodszky E, Siddiqi F, et al: PICALM modulates autophagy activity and tau accumulation. Nat Commun 5: 4998, 2014.

36. Baig S, Joseph SA, Tayler H, Abraham R, Owen MJ, Williams J, Kehoe PG and Love S: Distribution and expression of picalm in Alzheimer disease. J Neuropathol Exp Neurol 69: 1071-1077, 2010.

37. Parikh I, Medway C, Younkin S, Fardo DW and Estus S: An intronic PICALM polymorphism, rs588076, is associated with allelic expression of a PICALM isoform. Mol Neurodegener 9: 32, 2014.

38. Schjeide BM, Schnack C, Lambert JC, Lill CM, Kirchheiner J, Tumani H, Otto M, Tanzi RE, Lehrach H, Amouyel P, et al: The role of clusterin, complement receptor 1 , and phosphatidylinositol binding clathrin assembly protein in Alzheimer disease risk and cerebrospinal fluid biomarker levels. Arch Gen Psychiatry 68: 207-213, 2011

39. Dulabon L, Olson EC, Taglienti MG, Eisenhuth S, McGrath B, Walsh CA, Kreidberg JA and Anton ES: Reelin binds alpha3beta1 integrin and inhibits neuronal migration. Neuron 27: 33-44, 2000.

40. Sanada K, Gupta A and Tsai LH: Disabled-1-regulated adhesion of migrating neurons to radial glial fiber contributes to neuronal positioning during early corticogenesis. Neuron 42: 197-211, 2004.

41. Seshadri S, Fitzpatrick AL, Ikram MA, DeStefano AL, Gudnason V, Boada M, Bis JC, Smith AV, Carassquillo MM, Lambert JC, et al: CHARGE Consortium; GERAD1 Consortium; EADI1 Consortium: Genome-wide analysis of genetic loci associated with Alzheimer disease. JAMA 303: 1832-1840, 2010.

42. Jacobsen L, Madsen P, Jacobsen C, Nielsen MS, Gliemann J and Petersen CM: Activation and functional characterization of the mosaic receptor SorLA/LR11. J Biol Chem 276: 22788-22796, 2001.

43. Sager KL, Wuu J, Leurgans SE, Rees HD, Gearing M, Mufson EJ, Levey AI and Lah JJ: Neuronal LR11/sorLA expression is reduced in mild cognitive impairment. Ann Neurol 62: 640-647, 2007.

44. Louwersheimer E, Ramirez A, Cruchaga C, Becker T, Kornhuber J, Peters O, Heilmann S, Wiltfang J, Jessen F, Visser PJ, et al: Influence of genetic variants in SORL1 gene on the manifestation of Alzheimer's disease. Neurobiol Aging 36: e13-e20, 2015.

45. Sudoh S, Frosch MP and Wolf BA: Differential effects of proteases involved in intracellular degradation of amyloid beta-protein between detergent-soluble and -insoluble pools in CHO-695 cells. Biochemistry 41: 1091-1099, 2002.

46. Jiang Q, Lee CY, Mandrekar S, Wilkinson B, Cramer P, Zelcer N, Mann K, Lamb B, Willson TM, Collins JL, et al: Apo E promotes the proteolytic degradation of Abeta. Neuron 58: 681-693, 2008. 
47. Cook DG, Leverenz JB, McMillan PJ, Kulstad JJ, Ericksen S, Roth RA, Schellenberg GD, Jin LW, Kovacina KS and Craft S: Reduced hippocampal insulin-degrading enzyme in late-onset Alzheimer's disease is associated with the apolipoprotein E-epsilon4 allele. Am J Pathol 162: 313-319, 2003.

48. Rehman AA, Ahsan H and Khan FH: $\alpha-2-$ Macroglobulin: A physiological guardian. J Cell Physiol 228: 1665-1675, 2013.

49. Wilson MR, Yerbury JJ and Poon S: Potential roles of abundant extracellular chaperones in the control of amyloid formation and toxicity. Mol Biosyst 4: 42-52, 2008.

50. Yerbury JJ, Kumita JR, Meehan S, Dobson CM and Wilson MR alpha2-Macroglobulin and haptoglobin suppress amyloid formation by interacting with prefibrillar protein species. J Biol Chem 284: 4246-4254, 2009.

51. Cucullo L, Marchi N, Marroni M, Fazio V, Namura S and Janigro D: Blood-brain barrier damage induces release of alpha2-macroglobulin. Mol Cell Proteomics 2: 234-241, 2003.

52. Ozawa D, Hasegawa K, Lee YH, Sakurai K, Yanagi K, Ookoshi T, Goto Y and Naiki H: Inhibition of beta2-microglobulin amyloid fibril formation by alpha2-macroglobulin. J Biol Chem 286 9668-9676, 2011.

53. Kamboh MI, Minster RL, Feingold E and DeKosky ST: Genetic association of ubiquilin with Alzheimer's disease and related quantitative measures. Mol Psychiatry 11: 273-279, 2006.

54. Stieren ES, El Ayadi A, Xiao Y, Siller E, Landsverk ML, Oberhauser AF, Barral JM and Boehning D: Ubiquilin-1 is a molecular chaperone for the amyloid precursor protein. J Biol Chem 286: 35689-35698, 2011

55. Hiltunen M, Lu A, Thomas AV, Romano DM, Kim M, Jones PB, Xie Z, Kounnas MZ, Wagner SL, Berezovska O, et al: Ubiquilin 1 modulates amyloid precursor protein trafficking and Abeta secretion. J Biol Chem 281: 32240-32253, 2006.

56. Patel VP and Chu CT: Nuclear transport, oxidative stress, and neurodegeneration. Int J Clin Exp Pathol 4: 215-229, 2011.

57. Liu S, Zeng F, Wang C, Chen Z,Zhao B and Li K: The nitric oxide synthase 3 G894T polymorphism associated with Alzheimer's disease risk: A meta-analysis. Sci Rep 5: 13598, 2015.

58. Austin SA, Santhanam AV, Hinton DJ, Choi DS and Katusic ZS Endothelial nitric oxide deficiency promotes Alzheimer's disease pathology. J Neurochem 127: 691-700, 2013.

59. Liu F, Arias-Vásquez A, Sleegers K, Aulchenko YS, Kayser M, Sanchez-Juan P, Feng BJ, Bertoli-Avella AM, van Swieten J, Axenovich TI, et al: A genomewide screen for late-onset Alzheimer disease in a genetically isolated Dutch population Am J Hum Genet 81: 17-31, 2007.

60. Zhang X, Kurnasov OV,Karthikeyan S, Grishin NV, Osterman AL and Zhang H: Structural characterization of a human cytosolic NMN/NaMN adenylyltransferase and implication in human NAD biosynthesis. J Biol Chem 278: 13503-13511, 2003.

61. Hikosaka K, Ikutani M, Shito M, Kazuma K, Gulshan M, Nagai Y, Takatsu K, Konno K, Tobe K, Kanno H, et al: Deficiency of nicotinamide mononucleotide adenylyltransferase 3 (nmnat3) causes hemolytic anemia by altering the glycolytic flow in mature erythrocytes. J Biol Chem 289: 14796-14811, 2014.

62. Dreses-Werringloer U, Lambert JC, Vingtdeux V, Zhao $\mathrm{H}$ Vais H, Siebert A, Jain A, Koppel J, Rovelet-Lecrux A, Hannequin D, et al: A polymorphism in CALHM1 influences $\mathrm{Ca}^{2+}$ homeostasis, Abeta levels, and Alzheimer's disease risk. Cell 133: 1149-1161, 2008.

63. Demuro A, Parker I and Stutzmann GE: Calcium signaling and amyloid toxicity in Alzheimer disease. J Biol Chem 285: $12463-12468,2010$

64. Boada M, Antúnez C, López-Arrieta J, Galán JJ, Morón FJ, Hernández I, Marín J, Martínez-Lage P, Alegret M, Carrasco JM, et al: CALHM1 P86L polymorphism is associated with late-onset Alzheimer's disease in a recessive model. J Alzheimers Dis 20: 247-251, 2010.

65. Koppel J, Campagne F, Vingtdeux V, Dreses-Werringloer U, Ewers M, Rujescu D, Hampel H, Gordon ML, Christen E, Chapuis J, et al: CALHM1 P86L polymorphism modulates CSF A $\beta$ levels in cognitively healthy individuals at risk for Alzheimer's disease. Mol Med 17: 974-979, 2011.

66. Rubio-Moscardo F, Setó-Salvia N, Pera M, Bosch-Morató M, Plata C, Belbin O, Gené G, Dols-Icardo O, Ingelsson M, Helisalmi S, et al: Rare variants in calcium homeostasis modulator 1 (CALHM1) found in early onset Alzheimer's disease patients alter calcium homeostasis. PLoS One 8: e74203, 2013.

67. Perez-García GS and Meneses A: Effects of the potential 5-HT7 receptor agonist AS 19 in an autoshaping learning task. Behav Brain Res 163: 136-140, 2005.
68. Kehoe PG, Miners S and Love S: Angiotensins in Alzheimer's disease - friend or foe? Trends Neurosci 32: 619-628, 2009.

69. Oba R, Igarashi A, Kamata M, Nagata K, Takano S and Nakagawa $\mathrm{H}$ : The $\mathrm{N}$-terminal active centre of human angiotensin-converting enzyme degrades Alzheimer amyloid beta-peptide. Eur J Neurosci 21: 733-740, 2005.

70. Qiu WW, Lai A, Mon T, Mwamburi M, Taylor W, Rosenzweig J, Kowall N, Stern R, Zhu H and Steffens DC: Angiotensin converting enzyme inhibitors and Alzheimer disease in the presence of the apolipoprotein E4 allele. Am J Geriatr Psychiatry 22: 177-185, 2014.

71. Zlokovic BV, Deane R, Sagare AP, Bell RD and Winkler EA: Low-density lipoprotein receptor-related protein-1: A serial clearance homeostatic mechanism controlling Alzheimer's amyloid $\beta$-peptide elimination from the brain. J Neurochem 115 : 1077-1089, 2010

72. Jaeger LB, Dohgu S, Hwang MC, Farr SA, Murphy MP, Fleegal-DeMotta MA, Lynch JL, Robinson SM, Niehoff ML, Johnson SN, et al: Testing the neurovascular hypothesis of Alzheimer's disease: LRP-1 antisense reduces blood-brain barrier clearance, increases brain levels of amyloid-beta protein, and impairs cognition. J Alzheimers Dis 17: 553-570, 2009.

73. Tanokashira D, Motoki K, Minegishi S, Hosaka A, Mamada N, Tamaoka A, Okada T, Lakshmana MK and Araki W: LRP1 downregulates the Alzheimer's $\beta$-secretase BACE1 by modulating its intraneuronal trafficking $(1,2,3)$. eNeuro 2 : ENEURO.0006-15.2015, 2015

74. Karch CM and Goate AM: Alzheimer's disease risk genes and mechanisms of disease pathogenesis. Biol Psychiatry 77: 43-51, 2015.

75. Hollingworth P, Harold D, Sims R, Gerrish A, Lambert JC, Carrasquillo MM, Abraham R, Hamshere ML, Pahwa JS, Moskvina V, et al: Alzheimer's Disease Neuroimaging Initiative; CHARGE consortium; EADI1 consortium: Common variants at ABCA7, MS4A6A/MS4A4E, EPHA1, CD33 and CD2AP are associated with Alzheimer's disease. Nat Genet 43: 429-435, 2011.

76. Naj AC, Jun G, Beecham GW, Wang LS, Vardarajan BN, Buros J, Gallins PJ, Buxbaum JD, Jarvik GP, Crane PK, et al: Common variants at MS4A4/MS4A6E, CD2AP, CD33 and EPHA1 are associated with late-onset Alzheimer's disease. Nat Genet 43: 436-441, 2011

77. Lambert JC, Ibrahim-Verbaas CA, Harold D, Naj AC, Sims R, Bellenguez C, DeStafano AL, Bis JC, Beecham GW, Grenier-Boley B, et al: Cohorts for Heart and Aging Research in Genomic Epidemiology: Meta-analysis of 74,046 individuals identifies 11 new susceptibility loci for Alzheimer's disease. Nat Genet 45: 1452-1458, 2013

78. Griciuc A, Serrano-Pozo A, Parrado AR, Lesinski AN Asselin CN, Mullin K, Hooli B, Choi SH, Hyman BT and Tanzi RE: Alzheimer's disease risk gene CD33 inhibits microglial uptake of amyloid beta. Neuron 78: 631-643, 2013.

79. Bao J, Wang XJ and Mao ZF: Associations between genetic variants in $19 \mathrm{p} 13$ and $19 \mathrm{q} 13$ regions and susceptibility to Alzheimer disease: A meta-analysis. Med Sci Monit 22: 234-243, 2016.

80. Bradshaw EM, Chibnik LB, Keenan BT, Ottoboni L, Raj T, Tang A, Rosenkrantz LL, Imboywa S, Lee M, Von Korff A, et al: Alzheimer Disease Neuroimaging Initiative: CD33 Alzheimer's disease locus: Altered monocyte function and amyloid biology. Nat Neurosci 16: 848-850, 2013.

81. Khera R and Das N: Complement Receptor 1: Disease associations and therapeutic implications. Mol Immunol 46: 761-772, 2009.

82. Danik M, Chabot JG, Hassan-Gonzalez D, Suh M and Quirion R: Localization of sulfated glycoprotein-2/clusterin mRNA in the rat brain by in situ hybridization. J Comp Neurol 334: 209-227, 1993.

83. Schrijvers EM, Koudstaal PJ, Hofman A and Breteler MM: Plasma clusterin and the risk of Alzheimer disease. JAMA 305: 1322-1326, 2011.

84. Crehan H, Hardy J and Pocock J: Blockage of CR1 prevents activation of rodent microglia. Neurobiol Dis 54: 139-149, 2013.

85. Dunkelberger JR and Song WC: Complement and its role in innate and adaptive immune responses. Cell Res 20: 34-50, 2010

86. Sleegers K, Lambert JC, Bertram L, Cruts M, Amouyel P and Van Broeckhoven C: The pursuit of susceptibility genes for Alzheimer's disease: Progress and prospects. Trends Genet 26 : 84-93, 2010.

87. Kok EH, Luoto T, Haikonen S, Goebeler S, Haapasalo H and Karhunen PJ: CLU, CR1 and PICALM genes associate with Alzheimer's-related senile plaques. Alzheimers Res Ther 3: 12, 2011. 
88. Lopes AM, Ross N, Close J, Dagnall A, Amorim A and Crow TJ: Inactivation status of PCDH11X: Sexual dimorphisms in gene expression levels in brain. Hum Genet 119: 267-275, 2006.

89. Carrasquillo MM, Zou F, Pankratz VS, Wilcox SL, Ma L, Walker LP, Younkin SG, Younkin CS, Younkin LH, Bisceglio GD, et al: Genetic variation in PCDH11X is associated with susceptibility to late-onset Alzheimer's disease. Nat Genet 41: 192-198, 2009.

90. Haas IG, Frank M, Véron N and Kemler R: Presenilin-dependent processing and nuclear function of gamma-protocadherins. J Biol Chem 280: 9313-9319, 2005.

91. Connor JR and Lee SY: HFE mutations and Alzheimer's disease. J Alzheimers Dis 10: 267-276, 2006.

92.Robson KJ, Lehmann DJ, Wimhurst VL, Livesey KJ, Combrinck M, Merryweather-Clarke AT, Warden DR and Smith AD: Synergy between the C2 allele of transferrin and the $\mathrm{C} 282 \mathrm{Y}$ allele of the haemochromatosis gene (HFE) as risk factors for developing Alzheimer's disease. J Med Genet 41: 261-265, 2004.

93. Mariani S, Ventriglia M, Simonelli I, Spalletta G, Bucossi S, Siotto M, Assogna F, Melgari JM, Vernieri F and Squitti R: Effects of hemochromatosis and transferrin gene mutations on peripheral iron dyshomeostasis in mild cognitive impairment and Alzheimer's and Parkinson's diseases. Front Aging Neurosci 5: 37, 2013

94. Percy M, Somerville MJ, Hicks M, Garcia A, Colelli T, Wright E, Kitaygorodsky J, Jiang A, Ho V, Parpia A, et al: Risk factors for development of dementia in a unique six-year cohort study. I. An exploratory, pilot study of involvement of the E4 allele of apolipoprotein E, mutations of the hemochromatosis-HFE gene, type 2 diabetes, and stroke. J Alzheimers Dis 38: 907-922, 2014.

95.Lehmann DJ, Schuur M, Warden DR, Hammond N, Belbin O, Kölsch H, Lehmann MG, Wilcock GK, Brown K, Kehoe PG, et al: Transferrin and HFE genes interact in Alzheimer's disease risk: The Epistasis Project. Neurobiol Aging 33: 202.e1-202.e13, 2012.

96. Montoya SE, Thiels E, Card JP and Lazo JS: Astrogliosis and behavioral changes in mice lacking the neutral cysteine protease bleomycin hydrolase. Neuroscience 146: 890-900, 2007.

97. Suszyńska-Zajczyk J, Luczak M, Marczak L and Jakubowski H: Hyperhomocysteinemia and bleomycin hydrolase modulate the expression of mouse brain proteins involved in neurodegeneration. J Alzheimers Dis 40: 713-726, 2014.

98. Goedken M, McCormick S, Leidal KG, Suzuki K, Kameoka Y, Astern JM, Huang M, Cherkasov A and Nauseef WM: Impact of two novel mutations on the structure and function of human myeloperoxidase. J Biol Chem 282: 27994-28003, 2007.

99. Maki RA, Tyurin VA, Lyon RC, Hamilton RL, DeKosky ST, Kagan VE and Reynolds WF: Aberrant expression of myeloperoxidase in astrocytes promotes phospholipid oxidation and memory deficits in a mouse model of Alzheimer disease. J Biol Chem 284: 3158-3169, 2009.

100. Tzikas S, Schlak D, Sopova K, Gatsiou A, Stakos D, Stamatelopoulos K, Stellos K and Laske C: Increased myeloperoxidase plasma levels in patients with Alzheimer's disease. J Alzheimers Dis 39: 557-564, 2014.

101. Gauthier S, Kaur G, Mi W, Tizon B and Levy E: Protective mechanisms by cystatin $\mathrm{C}$ in neurodegenerative diseases. Front Biosci (Schol Ed) 3: 541-554, 2011.

102.Hansson SF, Andréasson U, Wall M, Skoog I, Andreasen N, Wallin A, Zetterberg $\mathrm{H}$ and Blennow K: Reduced levels of amyloid- $\beta$-binding proteins in cerebrospinal fluid from Alzheimer's disease patients. J Alzheimers Dis 16: 389-397, 2009

103. Hua Y, Zhao H, Lu X, Kong Y and Jin H: Meta-analysis of the cystatin $\mathrm{C}(\mathrm{CST} 3)$ gene $\mathrm{G} 73 \mathrm{~A}$ polymorphism and susceptibility to Alzheimer's disease. Int J Neurosci 122: 431-438, 2012.

104. Tizon B, Ribe EM, Mi W, Troy CM and Levy E: Cystatin C protects neuronal cells from amyloid-beta-induced toxicity. J Alzheimers Dis 19: 885-894, 2010.

105. Kaur G and Levy E: Cystatin C in Alzheimer's disease. Front Mol Neurosci 5: 79, 2012.

106. Butler JM, Sharif U, Ali M, McKibbin M, Thompson JP, Gale R, Yang YC, Inglehearn C and Paraoan L: A missense variant in CST3 exerts a recessive effect on susceptibility to age-related macular degeneration resembling its association with Alzheimer's disease. Hum Genet 134: 705-715, 2015.
107. Iqbal K, Liu F, Gong CX and Grundke-Iqbal I: Tau in Alzheimer disease and related tauopathies. Curr Alzheimer Res 7: 656-664, 2010.

108. Myers AJ, Kaleem M, Marlowe L, Pittman AM, Lees AJ, Fung HC, Duckworth J, Leung D, Gibson A, Morris CM, et al: The H1c haplotype at the MAPT locus is associated with Alzheimer's disease. Hum Mol Genet 14: 2399-2404, 2005.

109. Li T, Wen H, Brayton C, Laird FM, Ma G, Peng S, Placanica L, Wu TC, Crain BJ, Price DL, et al: Moderate reduction of gamma-secretase attenuates amyloid burden and limits mechanism-based liabilities. J Neurosci 27: 10849-10859, 2007.

110. Zhong Z, Ewers M, Teipel S, Bürger K, Wallin A, Blennow K, He P, McAllister C, Hampel $\mathrm{H}$ and Shen Y: Levels of beta-secretase (BACE1) in cerebrospinal fluid as a predictor of risk in mild cognitive impairment. Arch Gen Psychiatry 64: 718-726, 2007.

111. Cheng X, He P, Lee T, Yao H, Li R and Shen Y: High activities of BACE1 in brains with mild cognitive impairment. Am J Pathol 184: 141-147, 2014.

112. Modarresi F, Faghihi MA, Patel NS, Sahagan BG, Wahlestedt C and Lopez-Toledano MA. Knockdown of BACE1-AS nonprotein-coding transcript modulates beta-amyloid-related hippocampal neurogenesis. Int J Alzheimers Dis. 2011; 2011:929042. https://doi.org/10.4061/2011/929042.

113. Forsell C, Björk BF, Lilius L, Axelman K, Fabre SF, Fratiglioni L, Winblad B and Graff C: Genetic association to the amyloid plaque associated protein gene COL25A1 in Alzheimer's disease. Neurobiol Aging 31: 409-415, 2010.

114. Tong Y, Xu Y, Scearce-Levie K, Ptácek LJ and Fu YH: COL25A1 triggers and promotes Alzheimer's disease-like pathology in vivo. Neurogenetics 11: 41-52, 2010

115. Li D, Zhao H, Kranzler HR, Oslin D, Anton RF, Farrer LA and Gelernter J: Association of COL25A1 with comorbid antisocial personality disorder and substance dependence. Biol Psychiatry 71: 733-740, 2012

116. Keller M, Rüegg A, Werner S and Beer HD: Active caspase-1 is a regulator of unconventional protein secretion. Cell 132: 818-831, 2008

117. Heneka MT, Kummer MP, Stutz A, Delekate A, Schwartz S, Vieira-Saecker A, Griep A, Axt D, Remus A, Tzeng TC, et al: NLRP3 is activated in Alzheimer's disease and contributes to pathology in APP/PS1 mice. Nature 493: 674-678, 2013.

118. Cacabelos R, Martinez R, Fernandez-Novoa L, Carril JC, Lombardi V, Carrera I, et al. Genomics of dementia: APOE- and CYP2D6-related pharmacogenetics. Int J Alzheimers Dis 2012; 2012: 518901.

119. Bromek E, Haduch A and Daniel WA: The ability of cytochrome P450 2D isoforms to synthesize dopamine in the brain: An in vitro study. Eur J Pharmacol 626: 171-178, 2010.

120. Pilotto A, Franceschi M, D'Onofrio G, Bizzarro A, Mangialasche F, Cascavilla L, Paris F, Matera MG, Pilotto A, Daniele A, et al: Effect of a CYP2D6 polymorphism on the efficacy of donepezil in patients with Alzheimer disease. Neurology 73: 761-767, 2009

121. Liu M, Zhang Y, Huo YR, Liu S, Liu S, Wang J, Wang C, Wang J and Ji Y: Influence of the rs1080985 single nucleotide polymorphism of the CYP2D6 gene and APOE polymorphism on the response to Donepezil treatment in patients with Alzheimer's disease in China. Dement Geriatr Cogn Dis Extra 4: 450-456, 2014.

122. Counts SE, He B, Che S, Ginsberg SD and Mufson EJ: Galanin hyperinnervation upregulates choline acetyltransferase expression in cholinergic basal forebrain neurons in Alzheimer's disease. Neurodegener Dis 5: 228-231, 2008.

123. Steiner RA, Hohmann JG, Holmes A, Wrenn CC, Cadd G, Juréus A, Clifton DK, Luo M, Gutshall M, Ma SY, et al: Galanin transgenic mice display cognitive and neurochemical deficits characteristic of Alzheimer's disease. Proc Natl Acad Sci USA 98: 4184-4189, 2001

124.Zhou S, Zhou H, Walian PJ and Jap BK: CD147 is a regulatory subunit of the gamma-secretase complex in Alzheimer's disease amyloid beta-peptide production. Proc Natl Acad Sci USA 102: 7499-7504, 2005. 